\title{
Análise discursiva do Plano de Desenvolvimento Institucional do CEFET/RJ: uma proposta de resistência a um discurso institucional hegemônico ${ }^{1}$
}

Fábio Sampaio de Almeida (CEFET-RJ UnED) Maria Cristina Girogi (CEFET-Celso Suckow)

\section{Resumo}

Considerando as mudanças em curso na organização da rede federal de educação profissional e tecnológica, buscamos problematizar o papel do discurso como mecanismo de produção e manutenção de relações de saber e poder hegemônicas que engendram subjetividades de uma comunidade heterogênea como um projeto hegemônico em um documento oficial do CEFET/RJ. Nosso objetivo é identificar a construção discursiva da noção de comunidade como grupo que sustenta o discurso institucional de apoio ao projeto de transformação em Universidade Tecnológica, considerando de que modo o referido documento pode dar visibilidade à heterogeneidade que constitui uma instituição na qual coexistem os níveis médio, técnico e superior. Para tal, apresentamos uma análise discursiva do Plano de Desenvolvimento Institucional do CEFET/RJe, como referencial teórico, seguimos as propostas de uma análise do discurso enunciativa, que se orienta pelas noções de interdiscurso (MAINGUENEAU, 2005) e de dialogismo (BAKHTIN, 2000; 2004) e pelas relações entre poder, saber e subjetividade (FOUCAULT, 1987, 1996; 2004). Entendemos que nossas análises linguísticas remetem, no documento analisado, a duas reflexões relevantes. A primeira é uma valorização de saberes que relacionam a instituição a um ensino pautado na eficiência, produtividade, organização e desenvolvimento, semelhante a qualquer empresa comercial ou industrial, que prioriza principalmente atitudes necessárias no mercado de trabalho capitalista, $e$ em lugar de formação de um trabalhador, o adestramento, a docilização de corpos que possam ser úteis ao mercado de trabalho. A segunda seria a homogeneização da comunidade como grupo que, mais do que sustentar PDI, respalda dis-

1 O trabalho de onde se originou este artigo (ver GIORGI, 2012) centra-se na discussão sobre o papel dos ensinos médio e técnico no PDI do CEFET/RJ. cursivamente o projeto de Universidade Tecnológica.

Palavras-chave: discurso institucional; ensino profissionale tecnológico; produção de subjetividade; relações poder/saber. 
As instituições federais de educação profissional de nível médio sofreram recentemente uma reformulação. A maioria dos Centros Federais de Educação Tecnológica (CEFETs) e escolas técnicas foi transformada pelo governo Lula em Institutos Federais de Educação Ciência e Tecnologia (IFETs), e apenas os três mais antigos, do Rio de Janeiro, de Minas Gerais e do Paraná, não passaram por tal processo. O último já alcançou o nível de Universidade Tecnológica (antes mesmo da transformação das outras unidades em IFETs) e os dois primeiros, atualmente ainda CEFETs, pleiteiam o mesmo, contrariando a proposta governamental dos Institutos Federais Tecnológicos. Nesse contexto, percebemos nas políticas públicas federais um investimento na ampliação da educação profissional e tecnológica pública realizada especialmente na criação de Instituições de Ensino Superior que teriam, segundo o MEC, como princípio articular as dimensões do ensino, da pesquisa e da extensão. Dessa forma, na prática, extinguem-se instituições que eram apenas de nível médio, que passam a funcionar como instituições de ensino superior, com maior autonomia administrativa e pedagógica.

A complexidade desse contexto político e econômico atravessa o plano da discursividade local, materializando-se em documentos que chegam a ser exigência para o próprio funcionamento da instituição de nível superior, como será apresentado. No caso do CEFET/RJ, entendemos que o projeto de transformação em Universidade Tecnológica (UT) está estrategicamente redigido em um desses documentos, o Plano de Desenvolvimento Institucional (PDI).

No presente artigo, pretendemos identificar, por intermédio da análise desse PDI, a construção discursiva da noção de comunidade como grupo que sustenta o discurso institucional do CEFET/RJ de apoio ao projeto de transformação em UT, tendo em vista de que modo um documento pode representar ou dar visibilidade aos grupos e interesses que constituem os diversos níveis de ensino aí presentes, a saber: médio, técnico e superior.

Para tal, o texto está organizado em quatro partes. A primeira é uma breve apresentação da instituição. Na segunda, se problematizam o seu papel e as relações de saber e poder que a constituem. A terceira exibe o PDI e o contexto de produção que o instituiu como documento obrigatório para instituições de ensino superior. No quarto bloco, introduzimos o referencial teórico-metodológico e procedemos nossas análises. E por último, nossas considerações finais.

\section{O CEFET/RJ: entre o profissional e o tecnológico}

No que se refere à relação trabalho e educação, pode-se afirmar que há, desde os tempos do Brasil Colônia, a preocupação com os interesses da elite e a desvalorização de qualquer atividade relativa a trabalho. Ao longo dos anos, cada vez mais, 
reforça-se a ideia de que o trabalho manual está aliado ao povo, aos desfavorecidos da fortuna, ao passo que o intelectual é reservado aos homens de posses.

Dando um salto no tempo, é apenas no início do séc. XX que surgem, não por acaso, políticas públicas favoráveis ao ensino técnico-profissional no Brasil, a partir do momento em que se entende ser preciso diversificar as atividades econômicas em prol do nosso desenvolvimento industrial. Funda-se, então, a Escola Normal de Artes e Ofícios Wenceslau Brás, para formar mão de obra qualificada (ver BRANDÃO, 1997).

Acompanhando todas as mudanças que sabemos ter ocorrido no sistema educacional brasileiro, e após muitas denominações, chegamos ao Centro Federal de educação Tecnológica Celso Suckow da Fonseca - CEFET/RJ, instituição atual, que se define em sua página como um centro que:

(...) é desafiado e se desafia, permanentemente, a contribuir no desenvolvimento do Estado do Rio de Janeiro e da região. Atento às Diretrizes de Política Industrial, Tecnológica e de Comércio Exterior do país, volta-se a uma formação profissional que deve ir ao encontro da inovação e do desenvolvimento tecnológico, da modernização industrial e potencialização da capacidade e escala produtiva das empresas aqui instaladas, da inserção externa e das opções estratégicas de investimento em atividades portadoras de futuro - sem perder de vista a dimensão social do desenvolvimento. Assim se reafirma como uma instituição pública que deseja continuar a formar quadros para os setores de metalmecânica, petroquímica, energia elétrica, eletrônica, telecomunicações, informática e outros que conformam a produção de bens e serviços no país (Disponível em: www.portal.cefet-rj.br/a-instituicao/historico.html)

Tais palavras nos permitem compreender que a instituição tem características bastante específicas, não se configurando como uma instituição de ensino básico, tampouco como uma de ensino superior. Em suma, trata-se de uma instituição atualmente tão peculiar, que sequer pode ser chamada escola, uma vez que nela convivem, além dos ensinos Médio e Técnico, o Ensino Superior, com cursos de graduação e pós-graduação, lato e stricto sensu.

E é por conta dessa diversidade que recorremos a Foucault, no intuito de melhor entender de que modo o discurso estabelece relações de poder / saber e produz certos modos de subjetivação.

\section{Discurso, poder e produção de subjetividade na escola}

Foucault, a nosso ver, é fundamental, quando se pretende conceber um novo modo de entender o sujeito - não como ser pré-linguístico, mas sim constituído em meio a questões históricas, relações de poder, saberes. Foucault (1996) desenvolve ideias acerca da relação entre as práticas discursivas e os poderes que as atravessam, postulando a existência de diversos procedimentos 
em nossa sociedade que controlam e regulam a produção dos discursos.

Torna-se visível a relevância da linguagem como elemento, que, em lugar de representar, constitui uma realidade discursiva. Como consequência, o sujeito, para o filósofo, não preexiste à sua constituição na/pela linguagem e as subjetividades são também resultados de operações discursivas.

Não existem, portanto, estruturas permanentes que constituem a realidade; e o discurso, como prática social, é produzido desde relações de poder e não deve mais ser tratado como conjunto de signos, e sim como prática, que, em lugar de representar, de somente designar, pode construir os objetos sobre os quais fala (FOUCAULT, 2004, p. 55).

Entendemos que devemos estar atentos a essa produção de discursos na escola, espaço no qual a distribuição de poder e saber é reconhecidamente desigual, além de procurar descristalizar falas que se justificam a partir de processos educativos, que, muitas vezes, acreditamos serem inevitáveis ou naturais, quando esses são apenas decisões que, como afirma Jardine (2007), poderiam ter sido tomadas em outros sentidos. A escola nem sempre foi esse modelo que disciplina, normaliza, divide e distribui tempos e espaços, classifica, diagnostica, sanciona e o qual reproduzimos; esse modelo é simplesmente resultado de embates de poder. Uma escola com base na organização fabril, cujo papel transcende à formação educacional, tem como objetivo final formar corpos disciplinados e dóceis que não questionem e mantenham a hegemonia vigente: a do capital.

O sujeito do conhecimento constitui-se historicamente por meio de "um discurso tomado como uma conjuntura de estratégias que fazem parte das práticas sociais" (FOUCAULT, 1996, p. 11). Com base em Nietzsche, Foucault (1987) nos faz entender que o saber não é algo que se impõe ao sujeito, mas, ao contrário, algo que o origina. O saber seria "aquilo que se pode falar", o que tem valor, ou seja, aquilo que adquiriu o status de acadêmico, científico. Não são apenas conteúdos, mas relações de poder.

Imprescindível relacionar a questão dos saberes com a escola, que é, por um lado, lugar fundamental para a construção de subjetividades; e, por outro, instituição marcada e atravessada pela configuração social. Dessa forma, reiteramos que há que se discutir o modo como se estabelecem as relações de poder no âmbito da escola, sempre levando em conta o lugar que ela ocupa na configuração da sociedade atual.

Voltando à constituição peculiar da instituição CEFET/RJ, onde saberes diversos coexistem, seria ingênuo pensar que os docentes de níveis distintos seriam valorizados da mesma forma, ainda que muitos professores que lecionam no ensino básico também atuem na pós-graduação, por exemplo. Mas, como nos ensina Foucault - opondo-se à tese de que haja formas e sujeitos 
de conhecimento dados previamente, sem sofrer influências das condições de existência sociais, políticas e econômicas, as quais seriam simplesmente depositadas no homem -, relevante são as práticas sociais, sendo estas o conjunto de regras tácitas que devem ser obedecidas, que se relacionam com a constituição de domínios de saber. Na realidade, as práticas sociais constroem os domínios do saber, originando não só conceitos e objetos como também novas formas de sujeito. Nesse sentido, os antes valorizados saberes relativos ao ensino profissional de nível médio passam a ceder espaço àqueles vinculados ao ensino superior.

Outra contribuição foucaultiana relevante para nós seria a análise da relação entre as práticas sociais de controle e vigilância e o nascimento do poder, que permitem entender como se estabeleceu, ao longo do tempo, o nexo entre o sujeito e a constituição da verdade. Mais especificamente, as práticas judiciárias ocidentais no que tange ao modo de julgar o homem a partir de seus "erros" são um modo de definir tipos de subjetividade e formas de saber, pois originaram modelos de verdade que ainda fazem parte de nossa sociedade em diversos domínios, na política, no comportamento diário e, também, na ordem da ciência, uma vez que: "Até na ciência encontramos modelos de verdade cuja formação releva das estruturas políticas que não se impõem do exterior ao sujeito do conhecimento, mas que são, elas próprias, constitutivas do sujeito do conhecimento" (FOUCAULT, 1996, p.27).

É a partir da reforma e da reorganização dos sistemas judiciário e penal que surge o que Foucault chama de sociedade disciplinar: a sociedade contemporânea, que substitui o saber de inquérito por um saber de "vigilância", na qual vivemos até hoje e do qual a escola é um exemplo.

No próximo item apresentamos nosso córpus que, em nosso entendimento, é exemplar da sociedade disciplinar, proposta por Foucault.

\section{O PDI: um breve histórico}

Nos anos 90, como resultado de conceitos econômicos deslocados para a área educacional, difunde-se cada vez mais a ideia de que tudo pode e deve ser avaliado com o objetivo de melhorar a qualidade do que é produzido. Nesse sentido, é preciso controlar as instituições, e a LDB 9.394/96 legitima o já existente controle burocrático sobre as instituições educacionais, incluídos nestas professores, técnico-administrativos e alunos.

Em meio a esse contexto e como exemplificação de referido controle, origina-se o PDI, a partir de duas atribuições definidas na LDB de competência do MEC: o credenciamento e a avaliação institucional. Suas devidas regulamentações, contudo, são postergadas, uma vez que o plano passa a figurar no cenário nacional somente em julho de 2001, ao tornar-se um dos elementos obrigatórios dos processos de credenciamento das Instituições de 
Ensino Superior (IES), além de um dos itens a ser considerado na avaliação institucional.

Em março de 2002, por meio de uma resolução do CNE, outorga-se mais poder ao plano, que passa a ser obrigatório para o protocolo de autorização de cursos e de credenciamento de IES (SEGENREICH, 2005, p. 152).

Em 2002 são publicadas pelo MEC as Diretrizes para Elaboração do PDI, com o objetivo de dirimir quaisquer dúvidas com relação ao plano e servir como diretriz para sua elaboração. Segundo Segenreich, no entanto, essas diretrizes têm como real propósito:

[...] sacramentar o enfoque 'credencialista' conferido ao PDI na Resolução 10/2002 (CONSELHO NACIONAL DE EDUCAÇÃO, 2002). Tendo em vista a natureza normativa do documento, ele é uma boa fonte para avaliar o papel que o MEC espera que o PDI desempenhe dentro e fora da instituição universitária. (SEGENREICH, 2005, p. 153)

No mesmo ano, por meio da publicação de uma resolução reforça-se a ideia do PDI como instrumento de planejamento e avaliação ao estabelecer a obrigatoriedade geral de recredenciamento das universidades e IES do país, tornando-se o plano o centro da avaliação para o dito recredenciamento.

Esse pequeno histórico permite identificar uma contradição entre o documento que deveria ser uma referência de fato para a avaliação institucional numa perspectiva formativa e o documento que passa a ser condição para o credenciamento/recredenciamento das Instituições de Ensino Superior, servindo, a nosso ver, mais como instrumento de controle, do que como diretriz.

Em 2004, por força de lei, reforça-se a ideia do PDI como instrumento de controle, já que esse passa uma das etapas obrigatórias para garantir a uma instituição seu status de nível superior.

Em 2006, dispõe-se, por intermédio de decreto, acerca do exercício das funções de regulação, supervisão e avaliação de instituições de ensino superior e cursos superiores de graduação, além de, no sistema federal de ensino, exigir-se uma nova adequação dos procedimentos de elaboração e análise do PDI, que passa, então, a ser regulamentado.

Desse modo, consiste num documento em que se definem a missão da instituição de Ensino Superior e as estratégias para atingir suas metas e objetivos, pautados em indicadores de desempenho. Ou seja, trata-se, em resumo, de um instrumento legal para a aferição da qualidade da gestão; um plano estratégico.

É, portanto, como já visto, referência para qualquer critério ou processo de avaliação relativa a Instituições de Ensino Superior e, mais: uma exigência para que elas existam e se instituam como tal. 
Pode-se entender o PDI como resultado concreto e efetivo de uma política; um documento que não surge ao acaso, mas que, de fato, representa uma política de avaliações relacionada à tendência de aplicar a todas as instituições os mesmos princípios e métodos administrativos do mundo empresarial, em consonância com as políticas públicas que vêm sendo adotadas no país.

E assim, em meio a tantos discursos que se produzem pela e na comunidade CEFET/RJ, por grupos diversos, surge um documento privilegiado para, de certa forma, constituir discursivamente o que a instituição é ou pretende ser. Um documento elaborado exatamente com o objetivo de falar por essa comunidade - em que coexistem os ensinos Médio, Técnico e Superior, além de docentes que atuam ora no Médio e no Superior, ora no Técnico e no Superior, ora nos três níveis - a partir do ponto de vista do Ensino Superior.

O CEFET/RJ elaborou, até o momento, dois PDI: o primeiro referente ao período de 2005-2009 e o segundo ao de 2010-2014. Nossas análises se baseiam na versão impressa do segundo PDI, que está em vigor, por ter sido essa a distribuída aos servidores de todas as unidades, garantindo maior circulação dentro da instituição.

Passamos agora às considerações de ordem teórica e metodológica, no que tange à opção por uma perspectiva discursiva de análise dos enunciados do PDI do CEFET/RJ.

\section{Dialogismo e interdiscurso: por uma semântica da resistência no discurso e nos grupos sociais}

Buscando dar visibilidade ao papel da linguagem na construção de sentidos sobre a escola e seus atores em um texto institucional, recorremos a uma perspectiva discursiva de cunho sócio-histórico (BAKHTIN, 2000; 2004) e enunciativo (MAINGUENEAU, 2005; 2002).

Bakhtin (2000) nos ensina que os discursos envolvem a relação sujeito-linguagem numa determinada situação de comunicação, isto é, remetem ao diálogo entre interlocutores e entre discursos e compreendem a interação como ação inerente às práticas sociais; práticas essas sempre situadas em determinado contexto histórico e social e sujeitas a diversas coerções.

O autor prescreve que todo discurso é dialógico, construído tendo como base outro discurso, pelo qual, por conseguinte, é atravessado e cujas marcas carrega. Os sentidos não devem ser entendidos como estáveis ou preestabelecidos dentro de um enunciado, uma vez que este, unidade real da comunicação, atualiza-se a cada relação que se estabelece entre os interlocutores. E é no cruzamento de enunciados que se preserva a memória social. Em sendo assim, todo discurso é construído tomando como base um Outro, e suas marcas nos permitem um acesso a outras enunciações. 
Nesse sentido, a proposta de Maingueneau (2005) sobre o primado do conceito de interdiscurso é também relevante para o objetivo da pesquisa. $\mathrm{O}$ autor entende que qualquer prática discursiva se deve considerar a partir da alteridade, pois qualquer que seja a identidade que um discurso possa assumir, ela é sempre indissociável de seu Outro.

Visando operacionalizar a noção de interdiscurso, o autor propõe uma tripartição conceitual: universo discursivo, campo discursivo e espaço discursivo. Como afirma, estas não são unidades preestabelecidas e estáveis, e sim uma abstração conceitual.

O universo discursivo compreende o conjunto de formações discursivas de todos os tipos que interagem em uma dada conjuntura. Devido à sua grande extensão, Maingueneau afirma que esse é pouco útil ao analista e constitui apenas possibilidade de domínios a serem estudados. Neste artigo seriam todas as formações discursivas que atuaram e atuam na constituição de discursos da e sobre a educação.

Já campos discursivos são o conjunto de formações discursivas em concorrência - enfrentamento aberto, aliança, indiferença aparente, por exemplo, - entre discursos que possuam a mesma função social e que divirjam em relação à maneira de exercê-la. Os diferentes discursos sobre o papel da escola técnica, sobre o ensino profissionalizante ou sobre a educação tecnológica são exemplos de campos discursivos.

Finalmente, espaços discursivos são subconjuntos de formações discursivas cuja inter-relação é relevante para a análise. É o recorte que resulta das hipóteses fundadas no conhecimento dos textos e da história destes, que serão confirmadas ou rejeitadas no decorrer da pesquisa. Cabe acrescentar que a configuração do espaço discursivo deve ser assumida pelo pesquisador e, portanto, este deve explicitar os critérios que legitimam essa escolha.

É essa visão que norteia a seleção dos enunciados analisados neste artigo e de outros que constituíram o córpus da pesquisa. Buscamos observar de que modo se constroem os discursos em um documento institucional e, para tal, como os efeitos de sentido produzidos têm a ver com o lugar sócio-histórico de onde o tema é falado e o modo como é falado. Para este artigo, foram selecionados os enunciados que fazem referência, pelo uso do termo "comunidade", a um grupo de indivíduos que atuam verbalmente na sustentação do discurso institucional em questão.

Sabe-se que o que constitui efetivamente uma comunidade são os discursos que ela produz, por conseguinte nenhuma instituição pode existir enquanto tal sem produzir discursos, que a atravessem e a constituam. Assim, a partir de uma perspectiva discursiva, é certo que se deve compreender o PDI como discurso em meio a seu contexto de produção e, como afirmam Rodrigues e Rocha (2010, p. 207): 
[...] observar como os discursos estão-se construindo requer que os tomemos como um modo de apropriação da linguagem socialmente constituído. Sendo assim, mais do que com o conteúdo temático, os efeitos de sentido que se produzem têm a ver com o lugar sócio-histórico de onde o tema é falado e, consequentemente, com o modo pelo qual ele é falado. Trata-se de uma complexidade que só faz ratificar um modo de funcionamento discursivo compatível com os princípios de uma semântica global. (RODRIGUES; ROCHA, 2010, p. 207)

Nossa aposta é que, se existe um discurso que enuncia a partir do CEFET/RJ, Instituição de Ensino Superior, esse discurso não pode ser homogêneo e representar um único ponto de vista. Acreditamos, portanto, que seja possível identificar ao menos dois sujeitos que falem de lugares sócio-históricos, se não opostos, pelo menos distintos. Mesmo porque nenhum enunciador enuncia sozinho, sempre se podem identificar outras vozes, pela presença ou pelo apagamento.

A escolha da designação "comunidade" como modo de entrada no texto, então, é responsiva a uma dupla compreensão. Por um lado, o fato mesmo de o discurso implicar necessariamente a organização social de comunidades discursivas (MAINGUENEAU, 2005), ou seja, ele é elemento constitutivo dessa organização, na qual os sujeitos discursivos são produzidos ao mesmo tempo em que produzem textos. Por outro, o vocabulário constitui na perspectiva de uma semântica global um dos planos que integra a produção de sentido nos enunciados (MAINGUENEAU, 2005).

Destacamos que nos interessa a possibilidade de uma mesma unidade lexical ser explorada semanticamente no plano do discurso de modos distintos por diferentes formações discursivas, isto é, de uma mesma palavra designar, e assim, produzir diferentes referentes, ainda que no mesmo texto.

Nesse sentido, pretendemos reconhecer possíveis pontos de controvérsia, outras vozes enunciadas ao longo do documento que nos permitam melhor compreender a comunidade construída discursivamente no documento, desde os efeitos de sentido que nele se produzem, uma vez que acreditamos, como Rocha (2003, p. 202), na "possibilidade de o Mesmo já se constituir em pista para localizar o Outro (nos pequenos deslizamentos que se verificam)". Para tal, destacamos os enunciados nos quais o termo "comunidade" atua como sujeito de ações que possuem um traço semântico dicendi, seja uma fala mais explícita ou uma ação que implica indiretamente uma fala.

O termo "comunidade" aparece pela primeira vez na apresentação do PDI em dois momentos:

Este Plano de Desenvolvimento Institucional do Centro Federal de Educação Tecnológica Celso Suckow da Fonseca - CEFET/ RJ para o período 2010-2014, aprovado pelo Conselho Diretor na Sessão Extraordinária de 16 de dezembro de 2010, ao expressar avanço em relação às diretrizes estabelecidas no PDI 
2005-2009 apresentado ao Ministério da Educação com base no novo estatuto do Centro e na organização acadêmica atinentes aos Decretos 5.224 e 5.225, de 1o de outubro de 2004, reflete o posicionamento da comunidade interna no sentido de assumir a continuidade de uma trajetória de formação que congrega o desenvolvimento da educação tecnológica nas dimensões de ensino, pesquisa e extensão.

Todo PDI traz desafios àqueles que se constituem como agentes e beneficiários do projeto nele presente. No caso de uma instituição de educação tecnológica, sua comunidade acadêmica - docentes, técnicos-administrativos e alunos - e a sociedade - aí compreendidos diferentes grupos sociais, o mundo produtivo e o poder público constituído.

Apesar de o segundo enunciado explicitar a constituição dessa comunidade "docentes, técnicos-administrativos [sic] e alunos", outorga ao referente uma unicidade, uma homogeneidade no mínimo questionável, principalmente porque, como já afirmamos, se existe um discurso que enuncia a partir do CEFET/RJ, esse não pode ser homogêneo e representar um único ponto de vista. Mesmo porque nenhum discurso poderia. É, a nosso ver, no mínimo, redutor afirmar que, dentro do quadro heterogêneo que constitui essa ou qualquer instituição, existe uma comunidade homogênea que assume um movimento em nome do Ensino Superior.

Retomamos o fragmento que define "comunidade acadêmica" sobre o qual devem ser tecidas ainda algumas considerações. A primeira sobre a definição de agentes e beneficiários de uma instituição de educação tecnológica. Se "Todo PDI traz desafios àqueles que se constituem como agentes e beneficiários do projeto nele presente" e é necessário indicar quais são os agentes e beneficiários nessas instituições, é porque tais agentes e beneficiários são particulares. Os agentes seriam a comunidade acadêmica específica da instituição e no que se refere à sociedade - que cumpriria o papel do beneficiário - são especificados "diferentes grupos sociais, o mundo produtivo e o poder público constituído". Entendemos que, pela indefinição presente em "grupos sociais diversos" e pela impossibilidade de se vincular o "poder público constituído" a apenas um segmento das instituições públicas educacionais, estabelece-se um laço específico entre a instituição de educação tecnológica e o mundo da produção, que não estaria dado, não seria óbvio ou natural, mas que, inegavelmente, representa um laço que vem se construindo ao longo da história do nosso ensino profissional.

Percebemos que o ponto crucial gira em torno da questão da identificação do grupo ou dos grupos que discursivamente dão sustentação ao discurso do PDI. Para tal, identificamos, em um primeiro momento, duas designações que poderiam contribuir com esse processo: Comunidade e CEFET/RJ. Uma leitura detida do documento nos possibilita identificar traços que as distinguem. 
Enquanto ao CEFET/RJ se atribuía no plano uma identidade aparentemente individualizada de caráter institucional, a comunidade é identificada com diferentes grupos (docentes, técnico-administrativos e discentes) e muitas vezes colocada no mesmo nível da comunidade externa. Há, assim, uma oposição entre o lugar da instituição e o daqueles que a constituem, justificando nossa opção por centrar as análises no termo comunidade com o objetivo de identificar, no PDI em nome de quem se fala, quando se fala da comunidade do CEFET/RJ, ainda que não pensemos ser coerente essa cisão entre um lugar institucional e a comunidade formada por aqueles que constituem os coletivos que a ocupam.

Fragmento 1

\begin{tabular}{|c|c|}
\hline Fragmento & Termo dicendi \\
\hline $\begin{array}{l}\text { No exercício cotidiano de sua atuação, tal intenção im- } \\
\text { plica prosseguir em: } \\
\text { - investir permanentemente nas dimensões quantita- } \\
\text { tiva e qualitativa dos projetos de ensino, pesquisa e } \\
\text { extensão, levando em conta o contexto de desenvolvi- } \\
\text { mento e demandas apontadas no diálogo com atores } \\
\text { sociais e debatidas com a comunidade interna; (p. 15) }\end{array}$ & $\begin{array}{l}\text { apontadas } \\
\text { diálogo } \\
\text { debatidas }\end{array}$ \\
\hline
\end{tabular}

No primeiro fragmento, o enunciador do documento, ao reforçar a continuidade das ações que já são executadas no âmbito da instituição, a fim da ter "sua institucionalidade reconhecida como Universidade Tecnológica" (CEFET, 2010, p. 15), atribui ao CEFET/RJ o investimento permanente nas três dimensões de ensino, pesquisa e extensão. Leva em consideração, para isso, duas ordens de coisas estabelecidas: o contexto de desenvolvimento e as demandas.

Uma vez que não fica claro, a partir da leitura do texto, a que contexto se refere, passamos às considerações acerca das demandas, "apontadas" a partir do "diálogo" com atores sociais, que devem ser "debatidas" com a "comunidade" do CEFET/RJ.

Com relação à questão da demanda, entendemos haver no enunciado uma divisão em dois momentos, de diálogo e debate, nos quais os participantes são distintos. Faz-se, portanto, necessário perguntar quem seriam esses atores sociais ou, mais relevante, por que a comunidade interna é excluída deste grupo. Enquanto os que atuam socialmente determinam quais são suas demandas, a comunidade interna desempenha o papel operacional de debater modos de encaminhamento dessa demanda.

Desse modo, apesar de o uso de termos como "diálogo" e "debate" apontar para uma equivalência entre ações ou posicionamentos sociais, identifica-se na materialidade linguística a oposição que dá sustentação à visão taylorista de trabalho, por meio da qual o "mundo produtivo" pensa quais são as suas necessidades, restando à instituição formadora de mão de obra executar a tarefa 
de operacionalizar meios de atendê-las. Interessante notar que, ao contrário do que pode parecer, a ação de debater no enunciado em questão está subordinada à ação de dialogar, já que o debate realizado pela "comunidade interna" se realiza a partir do que já fora estabelecido no diálogo com os "atores sociais".

Sendo assim, esse falar nada mais é do que atender à vontade do outro, que não é a própria comunidade interna, que, nesse momento, tem a função de servir à externa ou pelo menos à sua parte significativa: o "mundo produtivo".

\section{Fragmento 2}

\begin{tabular}{|l|l|}
\hline Fragmento & Termo dicendi \\
\hline $\begin{array}{l}\text { [...] reflete o posicionamento da comunidade interna } \\
\text { no sentido de assumir a continuidade de uma trajetó- } \\
\text { ria de formação que congrega o desenvolvimento da } \\
\text { educação tecnológica nas dimensões de ensino, pes- } \\
\text { quisa e extensão. (p. 5) }\end{array}$ & \\
posicionamento \\
\hline
\end{tabular}

No fragmento 2, constrói-se discursivamente uma ação a partir de um "posicionamento" tomado pela "comunidade interna" que assume "a continuidade de uma trajetória de formação que congrega o desenvolvimento da educação tecnológica nas dimensões de ensino, pesquisa e extensão".

Analisando o caráter dicendi do verbo "refletir" e do substantivo "posicionamento", concluímos que é preciso identificar uma voz que tenha sustentado um posicionamento e qual foi esse posicionamento para que o mesmo esteja sendo refletido no discurso institucional. Identifica-se, assim, uma construção semelhante à noção de discurso narrativizado proposto por Sant'Anna (2004), segundo a qual há o apagamento de alguns dos constituintes da enunciação relatada.

Conforme a autora, no discurso narrativizado presente no gênero notícia apagam-se as referências de coenunciadores, de tempo e de lugar e de como o enunciador-jornalista haveria tido acesso às informações que relata. Apenas é possível verificar a existência de uma enunciação anterior por meio da presença de um termo de "força dicendi" que, no entanto, não esclarece o contexto dessa enunciação. Já no caso identificado no PDI, não são os coenunciadores e o contexto espaço-temporal que se apagam, mas sim o dito. É possível identificar um enunciador, a "comunidade interna", e um termo dicendi, o "posicionamento", mas não aquilo que efetivamente foi dito para garanti-lo.

O efeito produzido pelo apagamento da voz da comunidade interna faz crer na homogeneidade de sua opinião. Desse modo, o enunciador do PDI estabelece uma aliança entre o discurso institucional e o discurso da comunidade interna explicitada pelo verbo "assumir", garantindo respaldo ao projeto do PDI. 


\begin{tabular}{|l|l|}
\hline Fragmento & Termo dicendi \\
\hline $\begin{array}{l}\text { Desejava-se o reconhecimento externo do Centro } \\
\text { como Instituição de Ensino Superior, com ciência da }\end{array}$ & $\begin{array}{l}\text { concepção } \\
\text { decisões }\end{array}$ \\
importância da manutenção e crescimento dos cursos & \\
técnicos de nível médio, já firmemente estabelecidos. & \\
Desde então, como atestam a produção e a divulgação & \\
de documentos e eventos que materializam a concep- & \\
ção e as decisões da comunidade sobre o tema, a Insti- \\
tuição aguarda o encaminhamento do MEC ao pleito \\
apresentado oficialmente mediante exposição de mo- \\
tivos e projetos, notadamente em dezembro de 2005, \\
setembro de 2007 e abril de 2009. (p. 18)
\end{tabular}

As mesmas considerações poderiam ser feitas no fragmento 3 , com relação às decisões tomadas pela comunidade. Constrói-se a imagem da "comunidade" como sujeito que "concebe" e "decide", ou seja, atua discursivamente, mas se apaga novamente aquilo que foi dito, ficando apenas a lógica da aliança com o discurso institucional. Nele também é reforçada a oposição entre a "instituição", no papel de enunciador do PDI, e a "comunidade", ambos os sujeitos distintos e independentes, já que a cada um cabem diferentes ações.

Considerando a diversidade do quadro docente e discente da instituição (indiscutivelmente a maioria atuando no Ensino Básico), parece pouco crível o consenso no que se refere ao reconhecimento externo do centro como Instituição de Ensino Superior, já que isso seria desconhecer ou não reconhecer a comunidade pragmática da qual se faz parte.

\section{Fragmento 4}

\begin{tabular}{|l|l|}
\hline Fragmento & Termo dicendi \\
\hline As orientações internas da proposta de adesão ao & apreciadas \\
REUNI, apreciadas na comunidade e referendadas & \\
pelo Conselho Diretor, fortalecem e atualizam objeti- & \\
vos, estratégias e ações constantes deste Plano de De- & \\
senvolvimento Institucional, levando em conta que as & \\
diretrizes gerais desse Programa guardam consonân- & \\
cia com o projeto de Universidade Tecnológica que ar- & \\
ticula níveis de ensino e integra atividades de ensino, & \\
pesquisa e extensão. (p. 26) & \\
\hline
\end{tabular}

Relevante no fragmento 4, uma vez mais, a separação entre comunidade e dimensão institucional, nesse caso o Conselho Diretor. A primeira aprecia, enquanto o segundo referenda. A nosso ver, ou está omissa a ação de aprovar a proposta de adesão ao REUNI ou o Conselho Diretor, em lugar de referendar, apenas aprovou, sem que a comunidade tomasse uma decisão sobre o 
tema, visto que o verbo "referendar", dentro desse contexto específico, apontaria para o ato de aceitar algo que já foi previamente aprovado por outrem. Uma vez mais, se fala de comunidade em um projeto que apenas contempla o Ensino Superior. Além disso, a ação atribuída à comunidade, "apreciar", destaca apenas uma tomada de consciência e não um posicionamento efetivo.

\section{Fragmento 5}

\begin{tabular}{|l|l|}
\hline Fragmento & Termo dicendi \\
\hline $\begin{array}{l}\text { Investir nas ações de extensão já existentes e reconheci- } \\
\text { das pela comunidade interna e externa (p. 51) }\end{array}$ & reconhecidas \\
\hline
\end{tabular}

No fragmento 5, a comunidade interna é colocada em posição análoga à externa quanto ao papel de "reconhecer" ações de extensão já existentes no CEFET/RJ. O verbo de traço dicendi "reconhecer" indica um posicionamento passivo da comunidade em relação a uma ação ativa, a de investir, realizada por um sujeito que não é referenciado, mas que pode ser vinculado à instituição, já que o PDI é um discurso institucional.

\section{Fragmento 6}

\begin{tabular}{|l|l|}
\hline Fragmento & Termo dicendi \\
\hline $\begin{array}{l}\text { Apoiar a comunidade interna na elaboração de pro- } \\
\text { jetos a serem desenvolvidos mediante financiamento } \\
\text { externo (p. 70) }\end{array}$ & elaboração \\
\hline
\end{tabular}

Já no fragmento 6, a comunidade interna é construída como aquela que elabora projetos. Não obstante, o que parece ser uma ação efetiva de autonomia, na verdade, passa distante das atividades de planejamento da instituição, uma vez que a comunidade precisa ser apoiada na realização dessa ação, ainda que não se explicite por quem. Parece que a questão a ser destacada é o interesse que demonstra o enunciador institucional nos financiamentos externos de projetos, já que são eles que garantem as verbas que, além de dar destaque à instituição por sua atuação, propiciam a ampliação de condições de infraestrutura, de compra de materiais, livros e equipamentos.

No que tange ao fragmento 7, asseveramos que a aparente forma ativa presente no ato de "avaliar" que se atribui discursivamente à comunidade não se sustenta a partir do momento em que serão avaliados "objetivos, estratégias e ações" de um PDI que já possui, pelo menos no plano discursivo, o pleno apoio dessa comunidade. 


\begin{tabular}{|l|l|}
\hline Fragmento & Termo dicendi \\
\hline $\begin{array}{l}\text { Em consonância com a diretriz de democratização do } \\
\text { planejamento, gestão e avaliação institucional, este }\end{array}$ & avaliados \\
PDI deverá ter seus objetivos, estratégias e ações per- \\
manentemente acompanhados e avaliados pela co- \\
munidade do Centro, ensejando planos plurianuais \\
e operacionais específicos para efetivação das metas \\
estabelecidas. Nos planos operacionais serão conside- \\
radas as prioridades e definida a programação asso- \\
ciada à disponibilização de recursos.
\end{tabular}

Em resumo, se relacionamos as considerações feitas ao longo das análises, pode-se entender comunidade, como um sujeito homogêneo, a quem são atribuídas, em geral, tarefas de execução, distantes do planejamento da instituição. À comunidade interna cabe pensar um modo de encaminhar a realização das demandas da comunidade externa, representada pela figura do "mundo produtivo". Pensar cabe àqueles órgãos e Setores Institucionais que são designados separadamente e, em oposição à comunidade acadêmica, àqueles que certamente encabeçam a hierarquia do Organograma.

No próximo item serão apresentadas as considerações finais de nosso artigo.

\section{Breves considerações finais}

Tomando como base a relação poder/saber proposta por Foucault (2004), fazem-se necessários questionamentos acerca da valorização de determinados saberes em detrimento de outros, que propiciam em um determinado momento, por meio de uma imposição institucional, a substituição de uma lógica histórica e socialmente construída, que valoriza os ensinos Técnico e Médio, por outra que opta pelo ensino Superior como identidade institucional. Ainda que os primeiros possuam maior número de alunos, de docentes, além de maior reconhecimento social, pois é inegável que, quando se fala em CEFET/RJ, ainda "a antiga Escola Técnica", entra em cena o ensino de nível Médio e não o Superior.

Nossas análises linguístico-discursivas apontam a valorização de saberes que relacionam uma instituição de ensino à eficiência, produtividade, organização e desenvolvimento, que deve funcionar de forma semelhante a qualquer empresa comercial ou industrial. Valores que implicam uma formação que prioriza não só habilidade, mas principalmente atitudes necessárias ao mercado de trabalho capitalista. Em lugar de formação de um trabalhador, o adestramento, a docilização de corpos úteis ao mercado de trabalho. E, para tal modo de funcionamento, é fun- 
damental entender a comunidade como massa homogênea, que aceita e não questiona, que executa e não formula.

Para concluir, entendemos que em uma instituição peculiar que se pretende uma universidade tecnológica, na qual convivem níveis de ensino diversos, mesmo em um documento que se enuncie a partir do ponto de vista do Ensino Superior, seria possível identificar diferentes vozes e posicionamentos por meio de marcas explícitas de heterogeneidade. Entretanto, por mais que, reiteradamente, a comunidade seja dividida entre docentes, técnico-administrativos e discentes, é tratada como uma unidade, massa homogênea a quem só se atribuem ações para dar sustentação a projetos alheios. Uma comunidade única oposta, discursivamente, à figura da instituição CEFET/RJ.

\begin{abstract}
Considering the ongoing changes within the federal organization of professional and technological education, this paper aims at discussing the role of discourse as a mechanism of production and maintenance of knowledge and power hegemonic relationships that engender subjectivities in a heterogeneous community as a hegemonic project in an official document from CEFET/RJ. Our goal is to identify the discursive construction of the notion of community, in the sense of a group which holds the discourse that supports the project of institutional transformation from CEFET/RJ to Technological University, considering the way that the document brings visibility to heterogeneity in that institution, in which coexist different levels as high school, technical and graduation as well. To accomplish this task we performed an analysis of CEFET's Institutional Development Plan. As the theoretical framework is proposed an enunciative discourse analysis, based on the notions of interdiscourse (MAINGUENEAU, 2005), dialogism (BAKHTIN, 2000, 2004) and the relationship among power, knowledge and subjectivity (FOUCAULT, 1987, 1996, 2004). The linguistic analysis leads to a couple of relevant reflections: the first one relates teaching to efficiency, productivity, organization and development as it is the case of any capitalist enterprise where, instead of training the worker, inputs docilization of bodies that may be useful to the market; the second would be the homogenization of the community as a group, that not only sus-
\end{abstract}


tains PDI but also provides discursive support to the Technological University project.

Keywords: institutional discourse; technological and professional education; subjectivity production; relationship power/knowledge.

\section{REFERÊNCIAS}

BAKHTIN, M. Estética da criação verbal. São Paulo: Martins Fontes, 2000.

. Marxismo e filosofia da linguagem. São Paulo: Hucitec, 2004.

BRANDÃO, M. Da Arte do Ofício à Ciência da Indústria: a conformação do capitalismo industrial Dissertação (Mestrado em Educação); Programa de Pós-Graduação em Educação da Universidade Federal Fluminense, Niterói, 1997.

CEFET/RJ. CEFET/RJ, seu tempo e sua história. 90 anos de formação profissional. Centro de Memória, CEFET: Rio de Janeiro, 2007.

FISCHER, R. A paixão de trabalhar com Foucault. In: COSTA, M. (org.). Caminhos investigativos: novos olhares na pesquisa em educação. Rio de Janeiro: DP\&A, 2002.

FOUCAULT, M. Vigiar e Punir. Petrópolis: Vozes, 1987. . A verdade e as formas jurídicas. Rio de Janeiro: Nau, 1996. . A arqueologia do saber. $7^{\mathrm{a}} \mathrm{ed}$. Rio de Janeiro: Forense Universitária, 2004.

GIORGI, M. C. Da escola técnica à universidade tecnológica: o lugar da educação de nível médio no Plano de Desenvolvimento Institucional do CEFET/RJ. 2012. 278 f. Tese (Doutorado em Estudos da Linguagem) Universidade Federal Fluminense, Niterói, 2012.

JARDINE, G. Foucault e educação. Mangualde: Edições Pedago, 2007. MAINGUENEAU, D. Análise de Textos de Comunicação. São Paulo: Cortez, 2002.

. Gênese dos discursos. Curitiba: Criar Edições, 2005.

POLIDORI, M.M; MARINHO-ARAUJO, C. M.; BARREYRO, C. SINAES: perspectivas e desafios na avaliação da educação superior brasileira. Ensaio: aval. pol. públ. Educ., Rio de Janeiro, v. 14, n. 53, dez. 2006. Disponível em: <http://dx.doi.org/10.1590/ S0104-40362006000400002>. Acesso em: 2 jan. 2012.

RODRIGUES, I.; ROCHA, D. Implicações de uma perspectiva discursiva para a construção de uma metodologia de análise das práticas linguageiras. Gragoatá, Niterói, n. 29, 2010.

SANT'ANNA, V. L. A. O trabalho em notícias sobre o Mercosul: heterogeneidade enunciativa e noção de objetividade. São Paulo: EDUC, 2004. 
SEGENREICH, S. C. D. O PDI como referente para avaliação de instituições de educação superior: lições de uma experiência. Ensaio: aval. pol .públ .Educ. [online]. 2005, v.13, n.47, p. 149-168. Disponível em: <http://www.scielo.br/pdf/ensaio/v13n47/v13n47a03.pdf>. Acesso em: 2 jan. 2012. 